\title{
Desporto de crianças e jovens - um estudo sobre as idades de iniciação
}

\author{
Francisco M. Silva \\ Larissa Fernandes \\ Flórida O. Celani \\ Universidade Federal da Paraíba, João Pessoa, Brasil
}

https://doi.org/10.5628/rpcd.01.02.45

\section{RESUMO}

A elevada importância da prática desportiva, ao lado do acentuado aumento de competições num quadro desportivo altamente especializado, determina a necessidade de participações precoces e exige maior atenção na preparação dos jovens desportistas. No que pese os estudos sobre o assunto, persistem dúvidas sobre a idade em que as crianças estariam aptas para se iniciarem numa prática desportiva sistemática. $\mathrm{O}$ trabalho aqui apresentado procurou identificar as idades em que as crianças, na cidade de João Pessoa, estão sendo iniciadas na atividade desportiva, relacionando-as com as recomendações da literatura especializada. Foram entrevistados 93 treinadores de 10 modalidades, escolhidas entre as de maior representatividade no contexto desportivo do Estado. Uma ampla pesquisa bibliográfica revelou as idades mais recomendadas para iniciação desportiva nas diversas modalidades, cujos dados indicaram, para os desportos individuais, uma predominância na faixa dos $8-12$ anos, com média de 8,9 . Para as modalidades coletivas as recomendações situaram-se entre os 8-14 anos, com média de 11,7. Os dados dos questionários revelaram, para as modalidades coletivas, que $74 \%$ dos treinadores recomendaram como idade ideal a faixa dos 9-12, enquanto nos desportos individuais a predominância situou-se entre 5-10 anos, com 58\% das indicações. Verificou-se ainda uma marcante divergência entre as idades que os treinadores apontaram como ideais e aquelas em que, realmente, o processo está acontecendo, idades reais. As principais justificativas para essa divergência vão desde a imposição dos dirigentes à cobrança de resultados pelos pais e dirigentes.

Palavras-chave: Iniciação desportiva, iniciação precoce, treinamento de jovens

\author{
ABSTRACT \\ Children and youth in Sport. \\ A study about the ages of the beginning of sport practices
}

The importance of sport and the increase in the number of specialised competitions determines the necessity of precocious participation of youth in competition and a larger attention to their sporting preparation.

Doubts persist in the literature regarding the ideal age for children to begin systematic sporting practices. This work tried to identify the age children began sport practice in the town of João Pessoa (Brazil) and compare the results with the opinion of coaches regarding the ideal age to begin sporting practices within their fields.

93 coaches in 10 sporting fields (both collective and individual sports) were interviewed.

The results showed that: (i) in collective sports, $74 \%$ of coaches suggested as the ideal age to begin sporting practices the $9-12$ age group and (ii) in individual sports, $58 \%$ of coaches suggested as the ideal age to begin sporting practices the $9-12$ age group.

There is also a marked difference between the real starting age in sport and the opinion of the coaches in the combined fields questioned. The justifications for this difference can be found in the assessments/rules of the sporting directors/heads as well as in the pressure from the parents.

Key Words: Children and youth sports, ages to begin sporting practices, precocious participation 


\section{INTRODUÇÃO}

A marcante e cada vez mais crescente universalidade do desporto tem atribuído-lhe importantes tarefas e responsabilidades no que se refere à formação das crianças e jovens. No que pese as grandes e reconhecidas contribuições da prática desportiva para o desenvolvimento físico e psicossocial do ser humano, ainda é pequeno o número de estudos realizados na especificidade do treinamento com os mais jovens.

O nível de compreensão sobre a adequação da prática desportiva aos estágios de desenvolvimento e características psicomotoras da criança e do jovem apresenta-se, ainda, relativamente frágil, principalmente se considerarmos as particularidades das várias modalidades desportivas e seus efeitos no organismo. Mesmo em estudos mais recentes continuam a persistir dúvidas sobre as idades em que as crianças e jovens estariam preparados para se iniciarem numa prática desportiva sistemática e de que forma deveria ocorrer essa inserção. É importante assinalar que o treino com crianças e jovens tem nuances que o diferencia do treinamento dos adultos. Em razão das características e particularidades determinadas pelos níveis de desenvolvimento físico, psíquico e afetivo relacionados aos estágios de crescimento e desenvolvimento, torna-se imprescindível diferenciar os objetivos, os conteúdos e os processos de treinamento dos jovens e dos adultos.

Em primeira instância, as preocupações devem se orientar para situar a real dimensão da adequação desse processo à idade e ao nível de desenvolvimento atual da criança e do jovem, assim como as perspectivas de desenvolvimento a longo prazo. Indagações do tipo: com que idade as crianças estão aptas para se iniciarem na prática desportiva? que pré-requisitos deverão atender para se iniciarem numa prática desportiva especializada? há vantagens em se iniciar precocemente na prática de um desporto? são preocupações para as quais as ciências do desporto ainda não encontraram respostas e explicações satisfatórias. Há de se considerar que até pouco tempo o treino dos jovens foi uma reprodução ou, no máximo, uma simples adaptação dos procedimentos e organização do desporto de rendimento. "Os treinadores de jovens tendem a pautar seus pensamentos e condutas pelos estereótipos vigentes no treino dos atletas do mais alto nível de rendimento" (30, p.10).

$\mathrm{Na}$ teoria do treinamento, a temática tem sido abordada a partir de dois conceitos: treinabilidade e período crítico ou sensível. O primeiro consiste em definir se um gesto encontra-se no estágio ideal para ser desenvolvido, ou seja: O jovem ao iniciar sua preparação especializada já deverá ter adquirido um variado repertório motor e uma atitude positiva para aprender habilidades de complexidade progressiva? $\mathrm{O}$ segundo conceito se orienta no sentido de identificar o momento adequado à produção de determinados efeitos de treino. "Sensitivos são os períodos de treino em que as crianças dominam da melhor maneira possível as técnicas aprendidas" (20 p. 45). No processo de treinamento com jovens as orientações acerca das idades consideradas ideais para a iniciação desportiva são estabelecidas com base nas características condicionadas pelo desenvolvimento etário tendo como preocupação central contribuir para a formação dos jovens em seus vários aspectos (psicológico, físico, sócioafetivo) de uma forma equilibrada e harmoniosa. Durante as primeiras etapas do aprendizado desportivo deve-se estabelecer as bases para o rendimento elevado evitando exigências de resultados imediatos. Dessa forma, a prática desportiva infantil, mesmo orientada para a consecução de bons resultados, não pode deixar de privilegiar as contribuições dessa mesma prática na formação do ser humano. Para Filin (17), existem zonas de idades (psicológica e biológica) favoráveis ao processo de iniciação desportiva que poderão servir de parâmetros orientadores, facilitando assim os processos de seleção e iniciação à prática desportiva.

A respeito da idade para iniciação desportiva, identifica-se uma predominância de orientações para o plano das capacidades coordenativas e condicionais, notadamente no que concerne ao desenvolvimento dessas capacidades, sem, no entanto, relacioná-las com as necessidades e exigências da prática concreta do desporto. Pouco se conhece a respeito dos efeitos de uma atividade desportiva especializada sobre o organismo e a personalidade em formação. Marques expressa sua 
preocupação indagando: "Como apoiar os mais jovens no seu percurso para o alto rendimento sem comprometer a sua educação, limitar a sua personalidade, hipotecar a sua saúde" (22 p.17). Atualmente existe a tendência de se reduzir a idade de iniciação em muitas modalidades desportivas, criando dúvidas e gerando questionamentos em torno da chamada "especialização precoce", definida por Persone (29) como uma atividade desportiva predominantemente competitiva, com elevada dedicação aos treinamentos e desenvolvida antes da puberdade.

As razões pelas quais se procura justificar a prática desportiva precoce envolvem as características do atual sistema desportivo, a busca de êxitos e vitórias em curto prazo e as atitudes dos pais em relação ao envolvimento dos filhos na prática desportiva. A crescente importância social do fenômeno desportivo, ao lado de um acentuado aumento na oferta de competições num quadro desportivo cada vez mais especializado, passou a definir novas exigências no domínio da preparação e determinou a necessidade de participações e especializações cada vez mais precoces.

Nesse contexto torna-se imperiosa a necessidade de investigações no sentido de contribuir para a definição das faixas etárias mais adequadas à iniciação desportiva e orientar os processos de preparação em conformidade com as características e particularidades dos estágios de desenvolvimento das crianças e dos jovens.

Nessa linha de preocupação, o Laboratório de Estudos e Pesquisas do Treinamento - LEPET, da Universidade Federal da Paraíba, vem realizando um trabalho que procura estudar as idades de iniciação desportiva para identificar possíveis relações entre idade, nível de resultados e longevidade desportiva. O trabalho aqui apresentado, como parte do projeto acima referido buscou, identificar a idade considerada ideala e a idade realb em que as crianças estão sendo iniciadas na prática de uma atividade desportiva, a partir das opiniões dos treinadores e de autores de textos relacionados com o assunto na perspectiva de identificar pontos de convergência e divergência entre teoria e prática da iniciação desportiva e, ao mesmo tempo, contribuir para a definição de orientações relacionadas com a idade de iniciação em grupos de modalidades com características comuns.

\section{METODOLOGIA}

Metodologicamente, este trabalho, apesar de abordar a mesma temática, desenvolveu-se através de duas etapas, diferenciando-se pelos objetivos propostos e pelas fontes pesquisadas. A primeira etapa consistiu numa pesquisa bibliográfica para identificar na literatura especializada as principais tendências sobre as idades recomendadas para a iniciação desportiva. Na segunda etapa foi realizada uma pesquisa de campo envolvendo treinadores e professores, através da aplicação de um questionário para levantar informações relativas às idades de iniciação desportiva recomendadas e praticadas por essa mesma população.

A amostra foi constituída por 93 treinadores de 10 modalidades desportivas (Atletismo, Natação, Judô, Tênis, Ginástica Artística e Rítmica, Futsal, Futebol, Handebol, Basquetebol e Voleibol) da cidade de João Pessoa. O critério de seleção da amostra foi definido segundo a representatividade e importância que cada modalidade assume no contexto desportivo do Estado. Deste modo, foram escolhidos no mínimo um e no máximo três treinadores por modalidade, considerando as seguintes situações:

- Treinadores de clubes e associações onde exista a prática da iniciação desportiva

- Treinadores de seleções das categorias de base

- Treinadores de equipes das escolas privadas e públicas

- Treinadores de empresas, academias, etc.

- Professores de universidades, enquanto instituições de formação

Os dados coletados foram tratados estatisticamente e analisados qualitativamente conforme as suas naturezas, no sentido de permitir a comparação e análise dos mesmos à luz da teoria que fundamenta este trabalho.

\section{APRESENTAÇÃO E ANÁLISE DOS RESULTADOS}

\section{1 - Pesquisa bibliográfica}

De acordo com os objetivos e estratégias

metodológicas definidas para o projeto procurou-se 
identificar na literatura especializada as opiniões dos autores em relação à idade recomendada para iniciação desportiva nas diversas modalidades. Uma análise da bibliografia publicada nos últimos anos permite afirmar que o tema "Iniciação Desportiva de Crianças e Jovens" tem sido bastante discutido, constituindo-se assunto polêmico, porém pouco explorado nas suas implicações físicas, psicológicas e sociais. Verificou-se a existência de uma inconstância na abordagem metodológica e particularmente nas idades consideradas ideais para o início da prática desportiva organizada e sistemática.

O quadro 1, aponta indicações para a iniciação desportiva no conjunto das diversas modalidades e na especificidade de cada uma delas.

Quadro 1 - Idades recomendadas pelos autores para iniciação desportiva

\begin{tabular}{|c|c|c|}
\hline Modalidades ind. & Idade de inicação & Autores \\
\hline Atletismo & $\begin{array}{l}10-12 \\
7-8 \\
12-14 \\
8-12 \\
9-12\end{array}$ & $\begin{array}{l}\text { Bompa (1998), Filin (1996); Utecht in Filin, (1996) } \\
\text { Balsewitsch in Tubino, (1979) } \\
\text { Bondartchuck, A.(1989); Nilsson L. (1995); Oliver (1995) } \\
\text { Ferreira, P. (1989) } \\
\text { Fernandez, F. G.(1995) }\end{array}$ \\
\hline Natação & $\begin{array}{l}3-7 \\
7-9 \\
9-10\end{array}$ & $\begin{array}{l}\text { Vonhausen in Tubino (1979), Bauermeister in Tubino (1979) } \\
\text { Bompa (1994), Filin (1996) Draper, J (1999) } \\
\text { Caunsilmen in Filin (1990) }\end{array}$ \\
\hline $\begin{array}{l}\text { Ginásticas } \\
\text { (Artística e Rítmica) }\end{array}$ & $\begin{array}{c}6-11 \\
6-8\end{array}$ & Bompa (1998), Filin (1996), Persone (1983) \\
\hline Judô & $\begin{array}{c}8-10 \\
12\end{array}$ & $\begin{array}{l}\text { Bompa (1998) } \\
\text { Sobral (1994) }\end{array}$ \\
\hline Tênis & $6-8$ & Bompa (1998), Filin (1996) \\
\hline Média: 8.9 & Desvio: 2.5 & Variância: 6.61 \\
\hline Modalidades col. & Idade de inicação & Autores \\
\hline Basquetebol & $12-14$ & Bompa (1998), Filin (1996) \\
\hline Futebol & $\begin{array}{l}10-12 \\
12-14\end{array}$ & $\begin{array}{l}\text { Bompa (1998), Filin (1996), } \\
\text { Sobral (1994) }\end{array}$ \\
\hline Futsal & $10-12$ & Bompa (1998), Filin (1996) \\
\hline Handebol & 9 & Filin (1996) \\
\hline Voleibol & $\begin{array}{l}10-12 \\
11-13\end{array}$ & Bompa (1994), Filin (1996) \\
\hline Média: 11.7 & Desvio: 1.4 & Variância: 1.89 \\
\hline Desportos em geral & $\begin{array}{c}7-8 \\
8-12 \\
9-10 \\
6-14 \\
10-14 \\
10-12\end{array}$ & $\begin{array}{l}\text { Loth in Persone (1983), Baissas (s/data) } \\
\text { Bal'Selvich (1983), Riordan in Persone (1983), Coelho (1985), } \\
\text { Persone (1983), Hahn, E.(1989), Martin, D.(1983), } \\
\text { Marques (1990), Filin (1996), } \\
\text { Carnevali (1987), Proença, J.(1992), Arens O. (1983) } \\
\text { Weineck, J.(1999) }\end{array}$ \\
\hline Média Geral: 9.9 & Desvio: 2.5 & Variância: 6.19 \\
\hline
\end{tabular}


Pelos dados expostos no quadro anterior, constata-se uma certa divergência nas opiniões dos autores consultados. Apesar das discordâncias foi possível identificar tendências dominantes, em termos de faixas etárias com maior incidência de opiniões para os desportos individuais, para as práticas coletivas e para o conjunto das modalidades.

Para os desportos individuais, as idades mais recomendadas situam-se na faixa dos $8-12$ anos de idade com média de 8,9 anos e desvio de 2,5. Ainda em relação às modalidades individuais, verifica-se que entre o atletismo e a natação situam-se as maiores discrepâncias. A primeira com recomendações para iniciação mais tardia, mesmo sendo perfeitamente identificável uma predominância na faixa dos $8-12$ anos, enquanto na natação as orientações vão no sentido de que a iniciação ocorra em idades mais baixas.

As modalidades coletivas são as que apresentaram, em termos de recomendações teóricas, indicações para iniciação em idades mais avançadas com variações que vão dos 8 aos 14 anos, sendo que, na maioria das indicações, a faixa dos 10-12 anos foi a mais recomendada com média de 11,7 anos e desvio de 1,4. Em relação aos desportos em geral verificou-se uma grande variação de idade: 6 aos 14 anos. No entanto a tendência predominante aponta para os 8-12 anos, possibilitando a definição de uma tendência média em torno de 9,9 com desvio de 2,5.

Reforçando a idéia amplamente aceita de que a capacidade de rendimento desportivo depende da eficácia das exigências de rendimento e sua adequação aos níveis de desenvolvimento dos prérequisitos individuais, os quais se situam num complexo decorrente dos processos de crescimento, maturação e desenvolvimento, foi possível verificar uma convergência entre os autores estudados, possibilitando a definição de uma tendência predominante entre os 8-12 anos de idade. Verificase ainda que as modalidades individuais e coletivas, analisadas isoladamente, apresentam divergências no sentido de se recomendar que a iniciação nos desportos coletivos ocorra mais tardiamente do que nos individuais.

Finalmente, percebe-se que, segundo a maioria dos autores estudados, as crianças na faixa dos $8-12$ anos encontram-se na fase de desenvolvimento mais apropriada para a aquisição das habilidades básicas necessárias à maioria das modalidades desportivas.

\section{2 - Estudo empírico}

Nesta parte do trabalho serão apresentados e discutidos os dados levantados através do questionário (ver Anexo) aplicado aos treinadores, relativamente às idades recomendadas para a iniciação desportiva, partindo-se do pressuposto de que os treinadores em alguns casos, mesmo aceitando e defendendo uma idade ideal, praticam outra, neste trabalho denominada de idade real. Os dados obtidos com a aplicação do questionário estão sistematizados e apresentados de forma resumida no quadro 2 , considerando cada modalidade isoladamente e o conjunto das modalidades individuais e coletivas.

Quadro 2 - Idades recomendadas pelos treinadores

\begin{tabular}{|c|c|c|c|c|c|c|c|c|c|c|c|c|c|c|c|c|}
\hline \multirow{2}{*}{$\begin{array}{l}\text { Idades } \\
\text { (anos) }\end{array}$} & \multicolumn{7}{|c|}{ Modalidades coletivas } & \multicolumn{7}{|c|}{ Modalidades individuais } & \multicolumn{2}{|c|}{ Ind. e Col. $(a+b)$} \\
\hline & $\mathrm{H}$ & $\mathrm{v}$ & $\mathrm{B}$ & Fs & $\mathrm{Fb}$ & Soma(a) & $\%$ & $\mathrm{~A}$ & G & $\mathrm{J}$ & $\mathrm{N}$ & $\mathrm{T}$ & Soma(b) & $\%$ & Total & $\%$ \\
\hline $5-6$ & 0 & 0 & 0 & 2 & 3 & 05 & 10 & 0 & 4 & 5 & 5 & 2 & 16 & 37 & 21 & 22,5 \\
\hline $7-8$ & 0 & 2 & 2 & 2 & 1 & 07 & 14 & 1 & 0 & 3 & 2 & 0 & 06 & 14 & 13 & 14 \\
\hline $9-10$ & 6 & 5 & 6 & 5 & 3 & 25 & 50 & 2 & 2 & 0 & 2 & 3 & 09 & 21 & 34 & 36,5 \\
\hline $11-12$ & 5 & 3 & 2 & 0 & 2 & 12 & 24 & 3 & 0 & 0 & 2 & 0 & 05 & 12 & 17 & 18,3 \\
\hline $13-14$ & 0 & 0 & 0 & 0 & 1 & 01 & 2 & 4 & 0 & 0 & 2 & 0 & 06 & 14 & 7 & 7,5 \\
\hline Outras & 0 & 0 & 0 & 0 & 0 & 00 & 0 & 0 & 1 & 0 & 0 & 0 & 01 & 2 & 1 & 1,1 \\
\hline Total & 11 & 10 & 10 & 09 & 10 & 50 & 100 & 10 & 07 & 08 & 13 & 05 & 43 & 100 & 93 & 100 \\
\hline
\end{tabular}




\begin{tabular}{|c|c|c|c|c|c|c|c|c|c|c|c|c|c|c|c|c|}
\hline \multirow{2}{*}{$\begin{array}{l}\text { Idade re } \\
\text { Idades } \\
\text { (anos) }\end{array}$} & \multicolumn{7}{|c|}{$\begin{array}{l}\text { ciação desportiva } \\
\text { Modalidades coletivas }\end{array}$} & \multicolumn{7}{|c|}{ Modalidades individuais } & \multicolumn{2}{|c|}{ Ind. e Col. $(a+b)$} \\
\hline & $\mathrm{H}$ & V & $\mathrm{B}$ & Fs & $\mathrm{Fb}$ & Soma(a) & $\%$ & $A$ & G & J & $\mathrm{N}$ & $\mathrm{T}$ & Soma(b) & $\%$ & Total & $\%$ \\
\hline $5-6$ & 1 & 1 & 0 & 4 & 2 & 08 & 16 & 0 & 0 & 6 & 6 & 1 & 13 & 30 & 21 & 22,6 \\
\hline $7-8$ & 4 & 1 & 2 & 4 & 3 & 14 & 28 & 0 & 3 & 2 & 5 & 0 & 10 & 23 & 24 & 25,8 \\
\hline $9-10$ & 3 & 4 & 5 & 0 & 2 & 14 & 28 & 0 & 1 & 0 & 2 & 0 & 03 & 7 & 17 & 18,3 \\
\hline $11-12$ & 1 & 3 & 2 & 1 & 3 & 10 & 20 & 3 & 1 & 0 & 0 & 1 & 05 & 12 & 15 & 16,1 \\
\hline $13-14$ & 2 & 1 & 0 & 0 & 0 & 03 & 6 & 7 & 0 & 0 & 0 & 2 & 09 & 21 & 12 & 12,9 \\
\hline Outras & 0 & 0 & 1 & 0 & 0 & 01 & 2 & 0 & 2 & 0 & 0 & 1 & 03 & 7 & 4 & 4,3 \\
\hline Total & 11 & 10 & 10 & 09 & 10 & 50 & 100 & 10 & 07 & 08 & 13 & 05 & 43 & 100 & 93 & 100 \\
\hline
\end{tabular}

$H=$ Handebol; $V=$ Voleibol; $N=$ Natação; $B=$ Basquetebol; $J=J u d o ̂ ; ~ T=$ Tênis; $G=$ Ginásticas (Artística e Rítmica); Fs = Futsal; $\mathrm{Fb}=$ Futebol; $A=$ Atletismo

Nos dados apresentados verifica-se uma considerável divergência entre as opiniões dos treinadores sobre as idades que consideram ideais para a iniciação desportiva, quer no tocante ao conjunto das modalidades, quer no interior de uma mesma modalidade. Como se pode perceber, os dados expostos no quadro acima apontam variações que vão dos 5-6 anos até os 13-14. No entanto, ao se analisar a maior concentração de opiniões em torno das faixas etárias indicadas verifica-se o seguinte:

- Nas modalidades coletivas as faixas etárias dos 910 e 11-12 anos foram as que apresentaram maior concentração de opções com 25 e 12 casos respectivamente. De forma que nessas duas faixas etárias concentraram-se $74 \%$ das opiniões dos treinadores pesquisados.

- No conjunto das modalidades individuais as faixas etárias dos 5 - 6 e 9 - 10 anos são as mais indicadas com 16 e 09 ocorrências, respectivamente, das 43 apuradas, definindo um percentual em torno das referidas faixas da ordem dos $58 \%$.

- Uma análise conjunta das modalidades individuais e coletivas indica que 85 dos 93 treinadores estudados situaram suas opiniões nas faixas etárias dos 5-6 aos 11-12 anos, com destacada predominância para a faixa dos $9-10$ anos.

Dessa forma, foi possível identificar tendências bem definidas e distintas no conjunto das práticas desportivas individuais e coletivas. Para os desportos coletivos, reforçando a orientação predominante identificada na pesquisa bibliográfica, constatou-se que as idades de iniciação recomendadas são mais avançadas do que para os desportos individuais. Verificou-se, ainda, a ocorrência de diferenças significativas entre as modalidades de uma mesma categoria, sejam elas individuais ou coletivas. Ainda em relação ao quadro 2 , os dados relacionados com a denominada "idade real" apresentam o seguinte comportamento:

- Para os desportos coletivos, diferentemente das idades ideais, as maiores concentrações situaramse nas faixas dos 7-8 e 9-10 anos cada uma com 14 freqüências, representando $56 \%$ das opiniões manifestas.

- Nas modalidades individuais, as idades mais apontadas foram os 5-6 e 7-8 anos, com 13 e 10 casos respectivamente dos 43 analisados, merecendo destaque também a faixa dos $13-14$ anos com $21 \%$ das opções manifestas.

- No conjunto das modalidades individuais e coletivas quase $50 \%$ dos entrevistados afirmaram que estão iniciando seus alunos entre os 5-6 e 7-8 anos de idade. Essa situação comparada com o quadro das idades ideais, onde se verifica que apenas $36.5 \%$ dos entrevistados apontaram as idades dos 5-6 e 7-8 como ideais para a iniciação desportiva, indica uma certa divergência entre o que os treinadores estudados apontam como ideal e aquilo que, de fato, ocorre na prática do treinamento. Essa tendência fica reforçada ao se verificar que no quadro das idades reais fica nítida a tendência de uma distribuição mais equilibrada entre as três faixas etárias mais elevadas (9-10, 1112 e 13-14 anos), enquanto no quadro das idades 
ideais há uma forte concentração em torno dos 9 10 anos. Esses dados indicam que a iniciação desportiva, na prática dos treinadores entrevistados, ocorre em idades mais precoces do que aquelas que eles apontam como as mais indicadas.

Ao se comparar esses dados com as informações da literatura (Quadro 1), percebe-se uma maior proximidade entre a literatura e as tendências predominantes nas opiniões dos treinadores, em termos de idades ideais. No entanto, quando os dados da pesquisa bibliográfica são confrontados com as idades reais é possível identificar uma maior discrepância no sentido de reforçar a tendência para iniciação em idades mais baixas, que, apesar de praticadas, não são defendidas pelos treinadores entrevistados, até porque não estão respaldadas pela literatura especializada.

Efetivamente, o assunto está longe de ser considerado concluído. A atual situação revela um afastamento, até certo ponto incompreensível, entre aqueles a quem compete à aplicação dos conhecimentos próprios da Teoria da Educação Física e dos Desportos e as orientações fornecidas por esses mesmos conhecimentos, apesar da sua insuficiência e relativa fragilidade.

O estudo aqui apresentado procurou também identificar entre os entrevistados as razões para a divergência entre idades ideal e real.

A partir dos resultados obtidos na pesquisa foi possível expressar no Quadro 3 os principais motivos apresentados pelos treinadores como sendo justificativas para as idades consideradas ideais e aquelas em que de fato a iniciação desportiva está ocorrendo, neste trabalho denominadas de idades reais.

As justificativas para as idades ideais que os treinadores apresentam baseiam-se fundamentalmente em características psíquicas e cognitivas das crianças e jovens. Nestas idades, os principais fatores que os treinadores destacam nas crianças e jovens como propícios ao aprendizado desportivo são a ludicidade e as capacidades de percepção e facilidade para aprendizagem dos gestos. No plano das idades reais as justificativas se fundamentam em aspectos de ordem social, onde se sobressaem as cobranças de resultados por parte dos clubes e dos próprios pais.

Dessa forma, fica evidente o entendimento dos treinadores de que a idade apropriada para a iniciação desportiva é aquela em que o jovem se encontra mais apto e receptivo para exploração e desenvolvimento da sua ludicidade, da coordenação motora e com maiores potencialidades para o aprendizado de gestos específicos. Contudo, na prática, o que se percebe é a antecipação desse processo por imposições de clubes, escolas e muitas vezes, pela cobrança antecipada de participações em competições desportivas e consecução de resultados expressivos.

Quadro 3 - Principais justificativas para as idades ideal e real

\section{Idade ideal}

Ludicidade - $21 \%$

Percepção e Coordenação motora - 19\%

Aprendizado dos gestos específicos - 15\%

Relação criança, mundo e meio ambiente $-15 \%$

Precocidade / Bons resultados $-15 \%$

Maior capacidade / assimilação - 15\%

Idade real

Imposição do clube para competições e

cobrança de resultados imediatos $-36 \%$

Cobrança dos pais $-29 \%$

Dificuldade de acesso - $15 \%$

Falta de estrutura do clube $-11 \%$

Desmotivação das crianças - 09\%

\section{CONSIDERAÇÕES FINAIS E RECOMENDAÇÕES}

Pelos dados apresentados, não foi possível identificar uma idade específica ou ideal de iniciação desportiva, mas tendências médias por modalidades. Verificou-se que as modalidades desportivas, em razão das suas especificidades e características próprias, exigem idades diferenciadas para o processo de iniciação.

Ficou constatado que a maioria os treinadores ao falarem da idade para iniciação desportiva situam suas opiniões numa faixa muito ampla que vai dos 56 aos 11-12 anos, com forte concentração em torno dos 9-10 anos de idade, enquanto os dados da literatura indicam uma nítida tendência para os 8 12 anos de idade. 
Constatou-se ainda uma marcante divergência entre as idades que os treinadores apontam como ideais (9 -10 anos) e aquelas em que realmente o processo está ocorrendo (5 - 8 anos).

As principais indicações levantadas para justificar essa divergência vão desde a imposição dos dirigentes à cobrança de resultados imediatos por parte de pais e dirigentes.

Pelas conclusões obtidas é plausível e pertinente a formulação de algumas recomendações, tais como: A prática desportiva para as crianças e os jovens mesmo tendo como objetivo descobrir e orientar talentos para o desporto de rendimento e portanto orientada para a busca do campeão, não pode perder de vista os seguintes princípios:

- Contribuir prioritariamente para a formação da criança e do jovem, considerando a interdependência dos aspectos físicos, psicológicos e sócio-afetivos, de forma equilibrada e harmoniosa.

- Atender à aprendizagem multilateral e ao desenvolvimento e aperfeiçoamento das técnicas e movimentos básicos como pré-condição para a especialização.

- Dedicar atenção especial ao desenvolvimento do gosto pela prática desportiva e compreensão dos efeitos positivos dessa prática.

- Orientar as expectativas do iniciante de forma realista, atendendo às necessidades, interesses e possibilidades de cada praticante, evitando os modelos e imagens veiculadas pelo desporto de elevados resultados praticado pelos adultos.

- Evitar que a prática desportiva dos mais jovens se oriente pelos processos reguladores do máximo rendimento e do resultado elevado. O desporto deve se moldar no sentido de atender às necessidades dessa população, assumindo um papel formativo e adaptado às circunstâncias e características individuais.

\section{NOTAS}

a) Neste trabalho "idade ideal" é aquela apontada pelos treinadores e estudiosos da matéria (pesquisa bibliográfica)

b) Idade real é aquela em que, efetivamente, os alunos e atletas dos treinadores investigados e das equipes e modalidades integrantes da amostra iniciaram-se na prática desportiva.

\section{CORRESPONDÊNCIA}

Francisco Martins da Silva

Av. Edson Ramalho, 397 - Ap. 302 - Manaíra

CEP 58.038-100 - João Pessoa - PB

Brasil

[fmsilva@nutecnet.com.br] 


\section{BIBLIOGRAFIA}

1. AÑO, V. (1994) Planificación y organización del entrenamiento escolar. Atletismo Espanhol 465: 94-46. 2. ARENS, O. (1983) Young runners avoid specialize. Modern Athlete and Coach 21(1): 29 -30.

3. BAISSAS, M. (s/data) Que criança? Que desporto? Que aconselhamento? Atletismo: Cadernos Técnicos, Federação Portuguesa de Atletismo, 23:13-23. Lisboa.

4. BOMPA, T. (1994) Theory and methodology of training: The key to athletic performance. Kendall-Hunt, Dubuque, IA.

5. BOMPA, T. (1998) Training Guidelines for Young Athletes in Total Training for Young Champions. Human Kinetics, Champaign, IL. 6. BENTO, J. O. (1992) O Desporto: as crianças, os jovens e o rendimento. Câmara Municipal de Oeiras.

7. BERTHOINS, M. (1995). Effect of 12-week training programme on maximal aerobic (mas) speed and running time to exhaustion at $100 \%$ of MAS for students aged 14 to 17 years. J Sports Med. and Physical Fitness. 35 (4): 251-255.

8. BONDARTCHUCK, A. (1989) Selection and training of young hammer throwers. Modern Athlete and Coach. 27 (3): 37-39.

9. CARNEVALI, R. (1984) Dificuldads del entrenamiento com jovenes en los deportes de fuerza. Revista Stadium 18 (107): 48-50. 10. COELHO, O. (1985) Atividade física e desportiva. Livros Horizonte, Lisboa.

11. COSTA, A. M. (1991) A Especialização precoce na iniciação desportiva. Revista Treino Desportivo 19.

12. DIEM, L. (1977) Esportes para crianças - Uma abordagem pedagógica. $1^{a}$ edição, Editora Beta Ltda, Rio de Janeiro.

13. DRAPER, J. A. (1999) Growth, development and the junior athlete. In: Frank S. P. (Ed.) Better Coaching. Advanced Coach's Manual, Australia Sports Commission.

14. FERNANDEZ, F. G. (1995) La Formación del fondista Una propuesta de actuación para el monitor. Atletismo Espanhol: 38-41.

15. FERREIRA, P. (1989) Do Treino da criança e do jovem com especialista em meio fundo. Revista Atletismo 58: 30-34.

16. MOTA, J. (1993) A Periodização do treino com jovens. Revista Horizonte, 23:163-167.

17. FILIN, V. P. (1996) Desporto juvenil: teoria e metodologia. Centro de Informação Desportiva, Londrina.

18. FILIN, V.P. e VOLKOV, V. M. (1998) Seleção de talentos nos desportos. Mediograf, Londrina.

19. GODIK, M. A. e POPOV, A V. (1996) La Preparación del futbolista, Paidotribo, Barcelona.

20. GOLOMAZOV, S. e SHIRVA, B. (1996) Futebol: Treino da qualidade do movimento por atletas jovens. FMU, São Paulo.

21. HAHN, E. (1989) L'Entrainement sportif dos enfants, Vigot, Paris. 22. MARQUES, A. T. (1999) Crianças a adolescentes atletas: entre a escola e os centros de treino ... entre os centros de treino e a escola! - Actas do Seminário Internacional "Treino de Jovens", Secretaria de Estado do Desporto, Lisboa.

23. MARTIN, D. (1993) Entrenamiento multilateral y especialización precoce. Stadium, 16: 36-42, Buenos Aires. 24. MATVÉIEV, L. P.(1991) Fundamentos do treino desportivo, Livros Horizonte, Lisboa.

25. NILSSON, L. (1995) Selección de Atletas Jovenes para las Escuelas Deportivas en Suecia. In:Cuadernos de Atletismo. Real Federación Española de Atletismo 34:87 - 89.

26. OLIVER, A. Desarrollo y organización de los jóvenes atletas en España. In Cuadernos de Atletismo. Real Federación Española de Atletismo 34:91 - 99.
27. PLATONOV, V. N. e FESSENKO, S. L. (1994) Los sistemas de entrenamiento de los mejores nadadores del mundo. $1^{\circ} \mathrm{vol}$

Paidotribo, Barcelona.

28. PROENÇA, J. (1990) Metodologia do treino de meio-fundo e fundo. Revista Atletismo. 100: 73-75. Lisboa.

29. PERSONNE, J. (1983) Nenhuma medalha vale a saúde de uma criança. Livros Horizonte, Lisboa.

30. SOBRAL, F. (1994) Desporto Infanto-juvenil: prontidão e talento. Livros Horizonte, Lisboa.

31.TUBINO, M.J.G. (1979) Metodologia científica do treinamento desportivo. São Paulo: Ibrasa.

32. WEINECK, J. (2000) Biologia do Esporte. Editora Manole: São Paulo.

33. WEINECK, J. (1999) Treinamento Ideal. Editora Manole: São Paulo, $9^{a}$ edição.

34. ZHELEZNIAK, Y. D. (1993) Voleibol: Teoria y Método de la Preparación. Paidotribo: Barcelona. 


\section{ANEXO - QUESTIONÁRIO}

\section{APRESENTAÇÃO}

\section{Sr. Professor/treinador}

Este questionário destina-se à coleta de parte das informações necessárias à realização de uma pesquisa sobre iniciação desportiva, que está sendo conduzida pelos integrantes do Laboratório de Estudos e Pesquisa do Treinamento - LEPET, da Universidade Federal da Paraíba. As informações aqui levantadas serão utilizadas, exclusivamente, para a elaboração do referido trabalho e será resguardado o anonimato das mesmas. Nesta parte do trabalho objetivamos, prioritariamente, identificar a opinião dos professores/treinadores em relação à faixa etária ideal para a iniciação desportiva, além de verificar a faixa etária real em que essa iniciação está ocorrendo.

\section{IDENTIFICAÇÃO}

Local de Trabalho:

Modalidade em que trabalha:

Tempo em que trabalha com a referida modalidade:

Nível de escolaridade:

\section{QUESTÕES}

3.1. Dentre as faixas etárias abaixo, indique a que você considera ideal para a iniciação desportiva, na sua modalidade:
( ) 5 a 6 anos
( ) 7 a 8 anos
( ) 9 a 10 anos
( ) 11 a 12 anos
( ) 13 a 14 anos
( ) outros

3.2 De acordo com a resposta anterior, numere de 1 a 3, em ordem de prioridade, as três afirmações que mais justificam a sua opção.

( ) Identidade entre o caráter lúdico inerente ao desporto e a faixa etária apresentada.

( ) A criança que começa cedo obtém melhores resultados.

( ) Nessa idade os meninos/meninas encontram-se mais aptos para o desenvolvimento de habilidades motoras.

( ) Nessa idade, o desenvolvimento físico da criança é compatível com as necessidades da prática desportiva.

( ) Os meninos/meninas apresentam maior interesse pelos ensinamentos relacionados com a prática desportiva.

( ) A partir dessa idade, a criança já possui estruturas psicológicas capazes de suportar as exigências impostas pelo treinamento.

( ) É a idade ideal para favorecer a inserção e o relacionamento da criança com o mundo e o meio ambiente em que vive.

( ) Faixa etária ideal para desenvolver a percepção espaço-temporal e a coordenação geral das crianças.

( ) Contribui para um melhor desempenho técnico na modalidade.

( ) Outros 
3.3. Caso tenha sido influenciado por estudiosos, na concretização das opiniões apresentadas nas questões anteriores, indique os autores e títulos que fundamentam suas opiniões.

3.4. Na sua prática como professor/treinador, indique a faixa etária em que, de fato (idade real), está ocorrendo a iniciação desportiva das crianças e jovens.

( ) 5 a 6 anos
( ) 9 a 10 anos
( ) 13 a 14 anos

Caso a opção indicada na questão anterior, se apresente diferente da opinião que você manifestou na questão no 3.1, responda as questões seguintes:

3.5. Considerando as afirmações abaixo e a diferença entre as faixas etárias indicadas nas questões no 3.1 e 3.4 (idades ideal e real), numere de 1 a 3 , em ordem de prioridade, as afirmações que, na sua opinião, mais justificam a diferença apresentada.

( ) Desmotivação das crianças pela prática desportiva.

( ) Cobrança de resultados precoce por parte dos pais.

( ) Imposição do clube/ou instituição para participação em competições nas categorias mirins e infantis.

( ) O clube/ou instituição não apóia a prática desportiva na faixa etária considerada ideal.

( ) Falta de estrutura do clube/ou instituição, para o trabalho na faixa etária considerada ideal.

( ) O clube/ou instituição cobra resultados imediatos e constantes.

( ) Preciso do emprego, daí não interfiro em assuntos relativos ao aspecto administrativo das equipes.

( ) Pouca oferta de opções e dificuldade de acesso das crianças/jovens à prática orientada e sistemática de uma atividade desportiva.

( ) Outros

3.6. Aponte, numerando de 1 a 3 em ordem de prioridade, três desvantagens que essa divergência de idades pode vir a ocasionar.

( ) Pode causar alterações no desenvolvimento psicomotor.

( ) Dificulta a assimilação da técnica.

( ) O atleta deixa de conseguir bons resultados e acaba se desestimulando.

( ) Provoca problemas no sistema cardiorespiratório.

( ) Dificulta o desenvolvimento das habilidades motoras específicas.

( ) Favorece a criação e desenvolvimento de vícios e deformações motoras.

( ) Provoca problemas de ordem articular.

( ) Provoca lesões músculo-esqueléticas.

( ) Dificulta o desenvolvimento das qualidades físicas básicas e específicas.

( ) Antecipa a obtenção de resultados, mas reduz a vida atlética do praticante.

( ) Contribui para a realização de resultados elevados, mas provoca instabilidade nos resultados.

( ) Outros 